\title{
Values Related to Moral Behavioral Practice in Malay Students Context
}

\author{
Maizura Yasin ${ }^{1}$, Nur Surayyah Madhubala Abdullah ${ }^{1}$, Samsilah Roslan $^{1}$, Nor Wahiza Abdul Wahat ${ }^{1}$, \\ Norzihani Saharuddin ${ }^{1}$ \\ ${ }^{1}$ Faculty of Educational Studies, Universiti Putra Malaysia, Serdang, Selangor, Malaysia \\ Correspondence: Maizura Yasin, Faculty of Educational Studies, Universiti Putra Malaysia, 43400 UPM Serdang, \\ Selangor, Malaysia. Tel: 603-9769-8210. E-mail: y_maizura@upm.edu.my
}

\author{
Received: September 3, 2021 Accepted: September 28, 2021 Online Published: October 16, 2021 \\ doi:10.5539/ass.v17n11p170 URL: https://doi.org/10.5539/ass.v17n11p170
}

\begin{abstract}
Malaysia is a country that strives to instill noble or good morals and values among the young generation who will lead the country's development. The importance of values has been clearly stated under the principle of 'decency and morality, the fifth principle in Malaysian National Principles. Adhering to this principle requires constant effort and has its challenges. This study discusses the practices of moral behavior in the daily lives of Malay students. This study uses the case study design (one case, one place) and a qualitative approach to understand this phenomenon. Purposive sampling techniques and specific criteria were used in selecting the participants of this study. The ATLAS.ti 7 software was used to manage the data obtained through observation, interviews, and document analysis. The thematic analysis_technique was then utilized to analyze data obtained in this study. These findings show that personal noble values and institutional values are the core of moral behavioral values. Malay students understand the practice of moral behavioral values as a combination of personal values and the institutional values that work in balance to be manifested and practiced consistently in their daily lives. In conclusion, together, the Ministry of Education, schools, family institutions and the community play an important role in inculcating values related to the practice of moral behavior among students. It is suggested that future studies conduct a comparison of values related to moral behavior among various ethnicities as well as categories of students (disciplined and undisciplined groups).
\end{abstract}

Keywords: values, personal noble values, institutional values, moral behavior, students, Malay

\section{Introduction}

Values form the basis of an individual's moral conduct in their daily lives. Values are defined as a tendency to choose or agree with one condition over another; rational or irrational, whether something is good or bad, beautiful or ugly, normal or abnormal. All of these are central to the individual and community mental program (Hofstede, 1988). Meanwhile, moral values should be based on core values, specifically compassion and justice (Abdul Rahman, 1987). Maizura (2015) also defined moral behavioral conduct as the practice of pure conception of (enjoining the good and forbidding the evil), with principles and situations by emphasizing personal and institutional values to ensure the well-being of one's self, the society, and the nation.

The Malaysian government is committed to producing an ethical generation with high moral values. For this reason, instilling morality and values has become a national agenda, as emphasized in the country's constitution, the National Principles (Rukun Negara), and policies such as Vision 2020, National Education Philosophy, and the Malaysian Education Blueprint 2013-2025 (MEB, 2012). The aim is to ensure that all Malaysians can appreciate the values and practice the moral behavioral conduct of their daily lives to guarantee the country's continued sovereignty and face the challenges of ethics and morality. In addition, it aims to ensure the well-being of Malaysians of various races and cultures. Therefore, the new generation should exhibit exemplary moral behavioral practices and behaviors in line with society's values and socio-cultural norms and the rule and laws in Malaysia.

The process of instilling value starts from childhood to adulthood. Morals and values are always instilled into various aspects of life formally and informally, whether at home, school, or in the community. Kotaiah (2014) states that home is the first place while school and teachers are the second place to influence children's moral development. Parents can influence the moral development of their children through various means, among them through instilling religious beliefs in children (Tan \& Maizura, 2020). Previous studies have proven that parental 
moral values applied to children can help the moral development of their children (Melati et al., 2010). In addition, parents can also involve children in their family affairs, be role models in inculcating religious beliefs, communicate regularly and effectively such as practicing moral narratives with children and provide quality bonding time for children.

Under the formal Malaysian education system, after spending six to seven hours a day in school, Malaysian students spend a lot of time with family and socializing with other members of the community, especially the local community (MEB, 2012). Therefore, values instilled by the family institution, community, and school have influenced the development of moral behavior of Malay students (Maizura, 2015). In this regard, values possessed by an individual will determine the thoughts, feelings, and actions they would take in their daily life. In addition, according to Arthur, Wilson, Godfrey, Gray, Newton (2009), values are elements that are closely related to individual characteristics, while Adreas (2007) asserted that action is influenced by the understanding of values.

If parents spend less time with their children because they are busy pursuing careers, as a result, morality among such adolescents will decline (Dalmacito, 2013). The expectation on the parents and teachers is getting higher especially when the students are exposed to a variety of resources, social media and gadgets in this digital era (Gui, Maizura, Nur Surayyah, \& Norzihani, 2020). According to Morgan (2016), students spend too much time online and this will affect their moral development. This scenario raises concerns and influences various values related to behaviors that to some extent will undergo changes in both positive and negative directions. This will depend on the extent of understanding and appreciation of the values that have been taught at home as well as in school.

Morality is principles that concern the difference between right and wrong action or good and bad behavior. Morality is important and needed to be taught in school to produce students who are balanced and harmonious in intellectual, spiritual, emotional and physical aspects based on the National Philosophy of Education (Gui, Maizura, Nur Surayyah \& Norzihani, 2020). Students in high school are teenagers who seek self-identity by being supported by holding a variety of values. At this point they are easily confused and cling to values that do not support the practice of good moral behavior in their lives. The disciplinary problem among the students is one of the big challenges for the education system in our country nowadays. The problem becomes serious when the students lost their moral compass to discern what is right and wrong for their actions in their lives and also in their future career. Moral behavior is a manifestation of moral values and noble morals that exist in the individual that allows them to practice it in daily life (Maizura, 2015).

The concept of 'person_with noble characteristic' is a goal to be achieved in two subjects based on social studies such as the Islamic Education and Moral Education subjects (Noorzulina \& Maizura, 2021). Islamic Education and informal Moral Education are implemented in every school and the teachers have taught and instilled moral values to the students. However, the issue of school discipline is still a major topic (Kok, 2018) involving Malay, Chinese and Indian students in Malaysia. Once the discipline issue arises, the roles of parents and teachers in developing the morality of students will be questioned-by_the society. Formally, the responsibilities of teachers are not only teaching students, but also helping students to develop in every aspect including morality (Gui, Maizura, Nur Surayyah Madhubala, \& Norzihani, 2020). However, the parents also have a big responsibility to educate and inculcate values related to moral behavior to make sure the younger generations to be a noble character (Noorzulina \& Maizura, 2021). Parents, teachers and members in society should set noble values in each aspect to be a role model for students and teenagers. This act_will enhance the virtuous and moral values through various activities in daily life, as well as through the mass media.

The Malay community has its own set of values highly influenced by the Islamic religion and culture. These include values, such as trust, justice, honesty, cleanliness, modesty, kindness, and love for humans and animals, and plants. Inculcation of the culture and customs, politeness, respect, and mutual aid has long been entrenched in the Malay community (Noraiti, 2005). At the same time, the school institution plays an important role in instilling moral values through formal and informal education to all students regardless of their race and religion. Muslim students are required to learn Islamic Education from primary school until high school, while non-Muslim students in Malaysia_are required to study Moral Education. Furthermore, all students in Malaysia must take the Civic and Citizenship subject. This Civic and Citizenship subject aims to provide an overview of the education institution and the personal characteristics that must be present in the mind of every student. Values are also instilled informally through the schooling system in other subjects, such as cross-curricula elements and co-curricular activities. There are 18 values that need to be instilled among students throughout their schooling years, namely belief in God, responsibility, self-reliance, self-appreciation, hard work, gratitude, patriotism, freedom, courage, honesty, rationality, being kind, concern for others, respect, compassion, 
cooperation, humility and tolerance (MOE, 2016). Through the emphasis and application of these values in the school system can cultivate good character, which translates into good daily behaviors and practices.

Values are also instilled informally through the schooling system in other subjects, such as cross-curricula elements and co-curricular activities. There are 18 values that need to be instilled among students throughout their schooling years, namely belief in God, responsibility, self-reliance, self-appreciation, hard work, gratitude, patriotism, freedom, courage, honesty, rationality, being kind, concern for others, respect, compassion, cooperation, humility and tolerance (MOE, 2016). Through the emphasis and application of these values in the school system can cultivate good character, which translates into good daily behaviors and practices. The above discussion shows that Malay students have certain values in their lives as a result of socialization at school, home, and in the community. Graham, Meihdl, Beall, Johnson, and Zhang (2016) show that studies on moral behavior involving socio-cultural aspects, particularly race, are important for understanding moral behavior from a racial context

\subsection{Research Objective}

The objective of this study is to explore values related to moral behavior practices among Malay students in context of their daily lives. Among the specific objectives of this study is:

i. To explore values related to moral behavior practices among Malay students in context of their daily lives

\subsection{Research Question}

i. What are values related to moral behavior practiced by Malay students in their daily lives?

\section{Theoretical Basis of the Study}

The theory of Virtues Ethics (Aristotle, 1979) and the theory of social morality (Durkheim, 1961) are the theoretical basis in this study to provide understanding in exploring the values related to moral behavior in the daily lives of Malay students. The theory of Virtues Ethics can provide an idea of how values related to the practice of moral behavior can be explored in depth in this study (Abdul Rahman, 1999). The first theory that supports this study is the ethical theory of noble personality is one of the earliest theories in the writings of Aristotle in 384-322 S.M. which asserts about the personality, temperament and characteristics of noble character Essentially this theory supports virtues that have the concepts of justice, generosity, courage, honesty, patience and wisdom that play an important and significant role in the moral life of individuals and society.

Moreover, this theory of Virtues Ethics by Aristotle is defined as a tendency for a purpose and does not involve human feelings, abilities or powers of feeling (Aristotle, 1979). This is because man cannot be praised or reviled and is said to be good or evil just because of his feelings or because he is able to feel them. The tendency to achieve a goal will make a person a perfect human being. Aristotle also stated that to have a theory of Virtues Ethics can be achieved through training, practicing the personality until it becomes a habit by creating pleasure and the action makes the act pleasing to the individual.

In addition, one of the traits of a theory of Virtues Ethics (Aristotle, 1979) by adopting the middle path is something that is neither excessive nor too little. In this theory it considers excessive and too little actions to be evil, bad and reprehensible actions. This theory requires a person to act in the right way, behave at a moderate pace and be in the middle ground in all actions. This doctrine of the middle way cannot be applied to evil actions regardless of excess or deficiency because it is still considered a wrong action.

The second basic theory of this study is the Social Morality Theory (Durkheim, 1961). This theory states that moral individuals are those who abide by the rules set by the authorities and emphasize discipline in the context of societal life (Swartz, 2010; Zajda, 2009). Moral values are different and shaped relative between one society and another. This is because the holding of the concept of value does not depend on the authorities and the society in which they live. This theory makes human rules covering society as a guide based on criteria in determining moral actions (Durkheim, 1961, 1973; Schwartz, 1992). Social morality also refers to institutional values that include school institutions, institutions of community norms and religious institutions adhered to by the community.

\section{Research Method}

\subsection{Research Design}

This study utilized qualitative design, specifically the case study approach. The study was conducted on a one case, one location basis and involved eight participants. The study's participants were 16-year-old Malay students who attended a secondary school in the Federal Territory of Putrajaya, Malaysia. The researcher played the role of the main instrument in this study, and data were collected through face-to-face structured interviews, 
observation, and document analysis. The data obtained were analyzed using ATLAS.ti 7 software, and the thematic analysis was carried out manually by the researcher.

\subsection{Research Participant Selection}

Eight Malay students were selected through purposive sampling based on predetermined criteria. The participants selected should be ready and willing to share their experiences and opinions about the moral behavior they practice in their daily lives. The participants were asked to provide honest and open feedback during the interview. The observation process and document analysis were systematically conducted with the consent of the parties involved. The selected participants were also asked for their consent to participate in the study. Moreover, consent was also obtained from parents and the school. The students and parents involved were notified of the study's purpose, procedure, and ethics before commencing the data collection. There are three predetermined criteria that need to be met before a Malay student is selected as the subject of the study, namely:

i. Malay students who are in form four.

ii. Participate voluntarily and obtain permission from parents and the school after the researcher states the purpose, procedure and ethics of the study.

iii. Willingness of study subjects to share experiences and practices of moral behavior in daily life honestly and openly in the form of interviews, observations and document analysis.

\subsection{Research Location}

The study was conducted in a national secondary school in Putrajaya. The school was selected based on the nature and purpose of the study, ease of access, entry and permission, opportunities, and school size (Jorgenson, 1989; Spradley, 1980). Furthermore, the school was selected in light of the school's and students' willingness, permission, readiness to cooperate and participate in the study. Yin (2009) stated that data collection should be conducted at locations that are easy to enter and non-complex after permission to enter is granted. $\mathrm{Li}$ (2008) also emphasized that a positive attitude and mutual respect are important in getting continuous consent to conduct observations and interviews. In this case, the school's acceptance of the researcher's presence and the study's participants' cooperation during data collection was very good from the beginning of the study. Therefore, to ensure a positive attitude and continuous acceptance, the researcher tried to build a good rapport with the school's administrators.

\subsection{Research Limitation}

The study involved eight Malay secondary schools' students studying in a school in the Federal Territory of Putrajaya. All of these students are studying in a government-funded national secondary school. In this regard, all of the school's operating expenses are funded by the Government of Malaysia through the Ministry of Education Malaysia. Limitations in this study are involving Malay Muslim students who are in Form Four. In addition, all these students do not have disciplinary problems in school and are categorized as students who practice moral behavior in the school area and outside the school area. The limitations of this study also depend on the honesty of the study participants during the interview session, the behavior during the observation without participating in the school area and the writing of self-reflection of values related to the practice of moral behavior practiced in their daily lives. In addition, this study also took a long time to form a good report with the study participants to reduce the gap and raise the trust of the study participants towards the researcher. It should be noted that moral behavior practices and values examined were only limited to what was described verbally by the students, through the behaviors observed, and journal entries or self-reflection in relation to moral behavior they practice in their daily lives. The limitations of this study also depend on the extent to which the oral, written, and observed information are honest and true.

\subsection{Data Validity and Reliability}

A variety of strategies were used to ensure that the findings of this study are valid and reliable, which are prioritizing ethical issues in research, protecting the confidentiality of research participants' identities and locations, obtaining the consent of all parties involved in this study, and explaining the purpose and procedure of the study to the participants. 
Table 1. Strategies in Determining Validity and Reliability

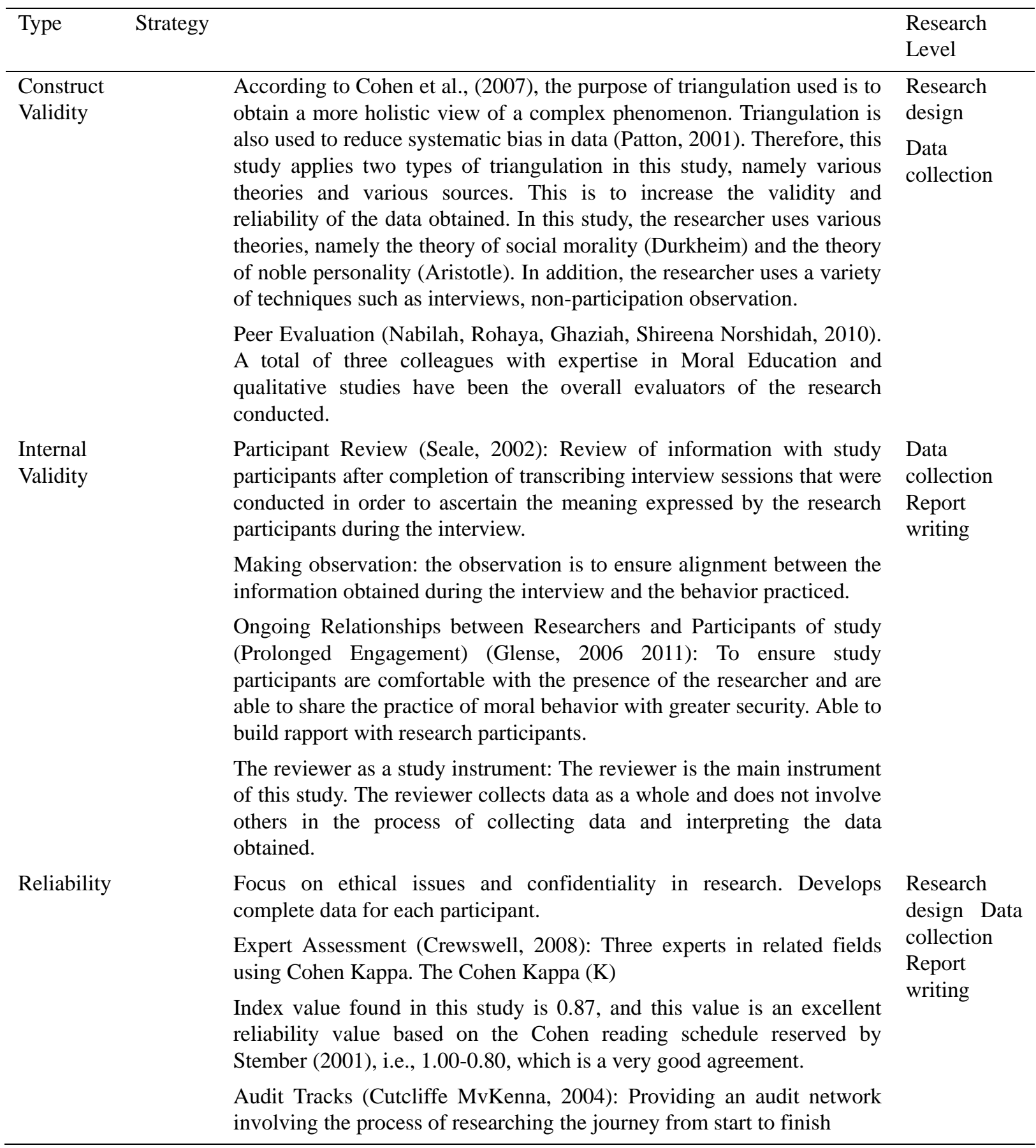

\subsection{Data Collection Procedure}

The data in this study were collected through semi-structured face-to-face interviews with research participants, document analysis, and observations. The interview protocol was used by the researcher to obtain data related to the value of students' moral behavior. Observation protocols such as checklist forms and document analysis protocols have been used by researchers in the process of obtaining data from various forms of sources. To look at data diversity and check for coherence, what was said during the interview session was compared with the behavior of the participants. In fact, through document analysis and observations, it has enriched the data from the aspects of values related to the moral behavioral practices of the participants.

The entire process of data collection took seven months to complete. Data collection procedures should be clear to facilitate researchers to conduct data collection in this study. According to Othman (2012), the data collection 
procedure focuses on the boundaries of the study to ensure that the data obtained can answer the research questions that have been set. In this study, the data collection procedure began with the determination of the study site, selection of study participants, permission to conduct the study, preparation of interview questions, and the work of performing interview data collection, observation and document analysis. Permission was obtained from study participants and parties involved such as parents, schools, the Department of Education and the Planning and Research Division, Ministry of Education Malaysia. The researcher began data collection by interviewing study participants.

Researchers also use non -participatory observation techniques in the classroom as well as in school areas and document analysis to obtain rich and meaningful data. The researcher started an interview session with the study participants and was followed by an interview session before observation and document analysis were conducted. Each information obtained from interviews, observations and document analysis is managed one by one to avoid confusion to the researcher. The data were obtained through interviews, observations and document analysis through the process of rearranging the information to facilitate the analysis of data on the thinking of moral behavioral practices of the study participants. The data management process is done simultaneously with the data collection process in this study to avoid data piles and situations that do not allow data to be analyzed after the data collection process is completed.

This is because the process of data analysis requires continuous and thorough research. After the completion of each interview session, the researcher proceeded to transcribe the interview session. The same goes for document observation and analysis. The researcher makes a summary and conclusion for each observation made to make it easier for the researcher to understand the data. Data obtained from interviews, observations and document analysis are still in the form of words, sentences and narratives of study participants that illustrate their understanding of their moral behavioral practices. In a qualitative research design that uses a case study approach, the researcher encodes quotations, sentences, words and narratives from study participants so that the data is easily interpreted as well as guarantees the ethics of confidentiality in the study. Furthermore, the process of coding and categorizing is done by the researcher to identify the formation of themes related to values related to the moral behavioral practices of Malay students.

\section{Findings and Discussion}

\subsection{Theme 1: Personal Noble Value Practices}

Personal noble values could be defined as the pure values appreciated and inculcated by individuals and practiced in their daily lives. In particular, the Malay students in this study believe that personal noble values they need to possess and demonstrate in their daily lives include kindness, concern for others, honesty, self-reliance, hard work, responsibility, compassion, and respect.

The excerpt below demonstrates RP7's understanding and practice of moral values, particularly kindness, in his moral behavior practices.

“...I saw my friend not bringing money to school to buy food. I helped my friends to buy food. In fact, I often give presents to family, teachers, and friends on their birthdays" (F1-1/RP7).

Most of the participants explained that they practice honesty, as shown in the statement given by RP4 “... I am very honest with myself and others" (F1-1/ RP4).

Furthermore, all participants practice self-reliance in their daily lives; RP2 expressed the view that:

“...I am self-reliant by doing something with my own efforts, especially in completing school work. I went to school by myself instead without asking for help from my mother and father to take me to school" (F1-1/RP2).

Responsibility is also another personal value practiced by the students in their daily lives. As asserted nu RP7:

“...I am responsible for the responsibilities given. For example, I am responsible for helping teachers maintain student discipline because I am a prefect. When my parents are not home, they gave me the responsibility to take care of the house for a while. By doing something with my responsibilities and not being selfish" (F1-2/RP7).

Hard work, compassion, and respect are also among the personal values practiced by the participants in their daily lives. The following excerpts show RP1 and RP5's views on personal values:

"... I am a diligent person, and I will do what I am assigned to do the best that I can. Furthermore, if I can do the task. I work hard to help my friends in terms of advising them to be better. I usually diligently complete the tasks assigned by my mom on time" (F1-1/RP1).

The following is an example of a statement regarding the compassion practiced by RP4: 
“...I practice showing compassion to everyone, including plants and the environment. I do practice my love for children or elders. I really like hanging out with children. I really love and care about the health and well-being of my pet. If I see my pet is sick, I will try to help it getting cured. I am not the type to take revenge on others. It will make my practice messed up if I have vengeance on anyone. (F1-1/RP4).

Respect is another value that is present in all participants. RP8 shared his view over the respect as in the following excerpt:

“... I respect parents, teachers, friends, and older people. I respect parents by speaking politely and not raising my voice. I also respect neighbours by speaking politely and respecting their privacy. (F1-1/RP8).

Another personal value is concern for others. The following is an example of concern for others demonstrated by RP5.

“...I show high concern for others. I also try to be polite and show courtesy. In addition, I show humility when I am socializing with friends at school to avoid misunderstanding. If I make a mistake, I try to apologize to friends or others who feel offended" (F1-1/RP5).

The findings clearly showed that Malay students understand personal values they need to possess as part of the moral practices in their daily lives. These values include kindness, concern for others, honesty, self-reliance, hard work, responsibility, compassion, and respect.

The findings of this study are in line with the findings of previous studies on personal values held by Malay students, namely respect, honesty, kindness, concern for others, and compassion (Muhamad Khairi, 2013). From a theoretical perspective, this view is in line with Islamic moral philosophy, which affirms the good values that need to be possessed by good Muslims (Al-Ghazali, 1898) and bring virtue to most individuals (Bentham, 1789); the values that are beneficial for oneself (Nietzsche, 1887); and the value of the obligation (Kant, 1797). On the other hand, the study's findings illustrate that the students did not perceive justice as a personal value that they need to possess and needs to be considered in their daily moral behavior practices. Previous studies have also shown that the value of justice is less emphasized by youths who are still in school (Muhammad Khairi, 2013). In this light, without justice, one's values and daily moral conduct are still incomplete. This is because the value of justice is considered the main value in one's daily moral conduct.

\subsection{Theme 2: Institutional Value Practices}

The next theme is the practice of institutional values. Institutional values are defined as values emphasized in an institution, either in school, the community, or religion. The study's findings show that the institutional value is linked to a school's rules and regulations, the value of community norms, specifically community spirit and respect, and religious values such as gratitude, humility, and mutual aid emphasized in Islamic religious institutions.

\subsubsection{Sub Theme 1: Values in School}

In the context of Malay students in the study, they see the school's rules as the moral behavioral practice that must is their responsibility. It is one of the moral behavioral practices in their daily lives. For example, RP1 is a disciplined student at school, and she arrives at school before the school bell rings. She obeys all the school rules at most times, but she has violated some rules, for instance, by bringing a mobile phone to school to make it easier for her to call her mother to fetch her from school. She realizes that even though her intention of bringing the phone is good, it still violates school rules. Hence, RP1 turns off the phone while in the school area and only turns it on after school hours (F2-1/RP1).

RP6 practices institutional values by adhering to all school rules, respecting teachers, completing schoolwork given by teachers, and packing his belongings at home (F2-1/RP6). From the observation, RP6 was found to be a student who does not violate any school rules (F2-2/RP6) because RP6 has never brought his mobile phone to school despite having one, always adhering to the school's dress code as well as other rules set by school (F2-3/RP6).

In addition, the eight participants of this study have shown that they practice values related to moral behavior in aspects of learning in school. Among them, they have a hardworking attitude, dedicated in school, like to ask questions to teachers if they do not understand, like to help classmates by giving guidance in subjects especially mathematics, English, Engineering Drawing and other subjects. Participants of this study also showed a helpful attitude towards teachers during and after the learning sessions. Among the actions of the participants in this study was to help erase the writing on the blackboard and to help bring other students' items and exercise books to be checked by the teacher to the teacher's room. 
Among the values related to moral behavior performed by these students is that they always maintain the cleanliness of the classroom without being instructed by the teacher and never take into account the work schedule to maintain cleanliness. All participants in this study are also proactive students in doing good to teachers and friends. others willingly help in learning and outside of learning sessions. The kindness of the participants in this study was affected when they liked to bring food to school to share with other friends.

Apart from that, the participants of this study also demonstrated the value of moral behavior through co-curricular activities in school by being actively involved in various club and association programs. The value of their responsibility is evident by gaining the trust of other peers and teachers to hold positions in clubs and associations in the school.

The value of respect is also practiced in the daily lives of the participants of this study in their daily lives either in school or outside of school. The study participants respect their subject teachers and all teachers in the school, schoolmates and even all employees in the community e.g., security guards, gardeners, canteen ladies and even cleaning staff at the school.

Compliance with school regulations is considered important as a practice of moral behavior among the Malay youth involved in this study. According to Sakhilah (2009), if a student violates school rules, the student is considered a problematic student for committing immoral behavior. Thus, it is clear that the value of adherence to the participants in this study is adhering to the rules and practice moral conduct in their daily lives. This finding shows that the Malay students understand that adherence to the school institutional value is a moral behavior that they should practice.

\subsubsection{Sub Theme 2: Community Norms Value}

Observations of the participants of this study indicate that compliance with societal or community values is part of their understanding of moral behavior. In addition, the values that exist within the community are in line with societal norms, especially community spirit and mutual respect in their daily lives. However, most participants admitted that they are less likely to demonstrate good moral conduct at the community level, for instance, participating in community and volunteer activities. This is because they found it hard to get involved with community-based activities outside of school.

The first participant explained that some neighbours show community spirit in his neighbourhood, but some show no community spirit at all. RP1 and his family demonstrate good moral practices like exchanging food with their neighbours, particularly on special occasions like during Ramadan. While RP1 never participated in voluntary work, such as in old folk homes, he has joined a voluntary activity at an orphanage with his mother and friends. Among the activities at the orphanage are playing with the orphans and donating clothes to them (F3-1/RP1).

RP2, RP3, RP4, and RP8 stated that they were only involved in communal activities within their neighbourhood. Apart from that, they admitted that they had never been involved in any community-based voluntary activity outside of school (F3-1/RP2-RP8). RP5 stated that he always smiles when he meets his neighbours. Sometimes SK5 is also involved in events organized by the community of residence (F3-2/RP5). RP6 has also attended family day programs organized by community members and visiting neighbours and friends during the festive season (F3-2/RP6).

Apart from that, all study participants demonstrated the community norm values, including showing respect to community members inside and outside of the school by greeting them and smiling at them. The study participants also demonstrate good moral behavior as they respect their teachers by greeting them or shaking their hands. This action was observed among male participants who would shake hands with male teachers, while female participants would shake hands with female teachers after each lesson. The participants always thank the teacher after each lesson session.

It was observed that one of the participants, RP1 practices the values of respect for older peers not only at school but also outside of school. He also shows respect to his relatives by greeting and speaking politely with them. Similarly, RP2 practices these values since childhood. RP2 parents always emphasize the need to practice respecting school teachers and others in daily life. This is because RP2 parents believe that the value of respect is the key to the moral conduct that one must adopt. For RP2, she respects her relatives just as much as she respects her parents by caring for their feelings.

RP3 also practices the value of respect in everyday life no matter where he is. For RP3, respect should be shown for older people, peers. RP3 shows respect to others by listening to their opinions. He also observed always greeting the teachers in his school regardless of whether the teacher was teaching him or not (F3-4/RP3). 
RP4 also practices community values and norms, such as respect in his school and at home. It was observed that RP4 shows high respect to all teachers. RP4 also showed respect towards his friends at school. RP4 shows his respect to all his classmates and students in other classes (F3-4/RP4). In short, all of the study participants practice good moral behavior based on community norms, specifically community spirit and respect regardless of the community they lived in.

The findings of this study are in line with the concept of morality, where behavior must consider one's personal and institutional values in their daily lives (Falikowski, 1990; Thiroux, 1977), as well as religious values. Furthermore, they align with the concept of morality based on society rules, which influence judgment, morality, or discipline in a society (Abdul Rahman, 1999; Abdul Rahman Chang, 1994). Similarly, values in society that align with societal values are also recognized by Durkheim (1961) as a system of societal rules and guidelines to determine whether a person's behavior is moral or otherwise. The findings of this study also correspond to the norms of the Malay community, which emphasizes the community spirit, mutual aid, and mutual respect between members (Noraiti, 2005).

Societal and cultural rules also determine one's moral conduct (Kohlberg, 1958). In addition, morality refers to all the rules of society and cultivating the pure nature and regulation of the society drafted based on the principles of autonomy, fairness, and altruism (Abdul Rahman, 1986). The institutional value of community spirit is seen to be in line with the findings of this study (Muhamad Khairi, 2013). In this regard, Malay students in this study understand that the value of mutual aid and mutual respect are part of the community institutional values that should be practiced in their daily lives.

\subsubsection{Sub Theme 3: Religious Values}

Malay teenagers in this study also saw those Islamic values, such as gratitude, modesty, and mutual aid, are closely associated with their moral behavior. This sub-theme is detailed with examples derived from the self-report prepared by RP1. RP1 stated that he always thanked the individuals who gave him something or assisted him, whether to the parents, teacher, siblings, and others (F4-1/RP1). As a sign of gratitude, RP1 always feels thankful for what he has now, even when he is an orphan and his family is living modestly and apart from that, RP1 empathized with the tribulation of others, especially when seeing poor people and those living in hardship (F4-2/RP1).

In addition, all research participants associate the practice of moderation and moral behavior with Islamic religious values. The self-reports showed that the participants recognize moderation as one of the moral behaviors they should practice daily. Subsequently, modesty is embedded in the daily life of RP3 as he grew up in hardship. Subsequently, this has made modesty a norm in RP3 life. RP3 saves money by bringing sandwiches and drinking water to school. He also likes to share his food with other friends (F4-1/RP3). According to his parents, RP3 is also a very modest person as he is willing to use his mother's 10 -year-old mobile phone with no shame (F4-2/RP3).

In addition, RP3 does not ask his parents for unnecessary things except for buying educational books and exercise books (F4-3/RP3). Furthermore, RP3 is a very moderate person in terms of clothing and appearances as he is willing to wear old school clothes and shoes as they are still in good condition without buying new ones (F4-4/RP3). RP3 also practices modesty with his friends as he does not speak of things that are not beneficial (F5-5/RP3).

All of the study participants viewed moral behavioral conducts such as gratitude and modesty are linked to religious values. In the meantime, only RP8 and RP4 associated the value of mutual aid and freedom with Islamic values. Other study participants were not linking these values with religious values. Thus, it clearly shows that the study participants linked the practice of moral behavior such as gratitude, modesty, and kindness with Islamic values

This study shows some of the 17 values emphasized in schools, including gratitude, modesty, and mutual aid, are linked to Islamic values (Vishalache, 2012). These values are divided into values in the development of self, family, environment, patriotism, human rights, democracy, and peace and harmony (Curriculum Development Centre (2005) that encompasses the development of personal value and institutional value indirectly. This study also showed that the Malays prioritize Islamic values when dealing with everyday situations (Noraiti, 2005).

In brief, the study participants understand that moral behavioral practices are based on their personal and institutional values instilled in the school, their community, and religion. In this light, balanced practices of these values could ensure the students possess good moral behavior in line with their personal standards and standards set by the societal norms and Islamic law. 


\section{Conclusion, Implications and Suggestions}

Students' understanding of the values and moral behavioral practices influences their actions and decisions in facing their daily moral dilemmas. In this regard, continuous efforts are highly needed from family institutions, schools, and the community to build proper understanding and accordance with the Malaysian social welfare in practicing moral behavior. In practicing moral behavior, students should not separate or divide the value of moral behavior practices as personal value and institutional value. Instead, they need to adopt institutional values as part of their personal values. This is because the segregation of such values will disallow the students from seeing institutional values as holistic values that complement their personal values.

The implications of this study are practical for parents in giving the sense that the process of application of noble personality values should be given serious attention in the family institution which encompasses noble values as a whole. This is very important to ensure that each child is able to make those values as their personal noble values, also making it as a habit to practice voluntarily on a consistent basis. Next, the implications of this study are for education in schools. It includes school administrators, teachers, counselors, staff in schools who set an example to students as an indirect learning process and have a tremendous impact on the moral development of the students. Counselors and teachers are encouraged to be more creative in planning activities that can instill institutional values and cultivate students' personal values towards ensuring that they become virtuous human beings in their daily lives and future careers.

Several suggestions can be put forward for family members, schools, and the community to help Malays students build a clear understanding of moral behavioral practices in their daily lives. First, the students need to have a clear and strong understanding of what values entail when teaching and instilling values such as integrity and fairness. For instance, the study found that Malay students did not prioritize justice as an important value even though justice and morality are particularly emphasized in Islam. Thus, the students need to understand the value of justice.

The second suggestion is that families, schools, and communities should impart the correct understanding of moral behavior in the students' daily lives, for instance, emphasizing the value of fairness to guide students while making decisions, especially when facing a moral dilemma that requires them to make decisions and act on the decisions in their daily lives. In this regard, the family institution has an instrumental role in shaping the value of moral behavior in their daily lives as students spend the most time with their families.

Further research in this field should ensure high moral behavioral practices in the students' daily lives. For example, future research may compare the value of the moral behavior practices between Malay students and students from other races. Moreover, researchers could conduct a thorough study on the roles of personal and institutional values in shaping moral behavior practices among students. It is hoped that the findings of this study will contribute to the development of knowledge and help improve students' moral behavior conduct in their daily lives.

\section{References}

Al-Ghazali, M. (1898). Revival of the religious sciences (Vol. 3). al-Matba'a al-azahariya.

Ali, S. S. (2009). Moral orientation in form four students. Doctor of Philosophy thesis unpublished. University of Malaya. Malaysia.

Andreas, P. (2007). Motivation, moral judgment, and the justication of mortality. Unpublished Doctoral Thesis in University Durham.

Aristotle. (1979). The Nicomachean ethics. Translated by Thomas, J.A.K., Penguin Books.

Aroff, A. R. Md. (1984). The purpose of Moral Education: An evaluation of the objectives of the Moral Education project in Malaysia. Journal of Educators and Education, 6, 52-60.

Aroff, A. R. Md. (1986). Introduction to Moral Education. Publisher Fajar Bakti Sdn. Bhd. Petaling.

Aroff, A. R. Md. (1999). Moral Education: Theory of ethics and moral practice. Publisher of University Putra Malaysia.

Aroff, A. R. Md., \& Hoon, C. L. (1994). Moral Education. Longman Malaysia Sdn. Bhd.

Arthur, J., Wilson, K., Godfrey, R., Gray, B., \& Newton, N. (2009). Values and characters: Higher education and employment. University of Birmingham.

Aslido, N. Z. S. De., \& Yasin, M. (2021). 'Noble character' as a focus in Moral Education in Malaysia. In K. J. Kenndy (Ed.), Social studies education in South and South East Asian Contexts (1st ed., pp. 14-17). 
Routledge. https://doi.org/10.4324/9781003057598

Balakrishnan, V. (2012). The dilemma of real life in Moral Education. Publisher of the University of Malaya. Malaysia.

Bentham, J. (1789). An introduction to the principles of morals and legislation. Oxford Clarendon Press. https://doi.org/10.1093/oseo/instance.00077240

Curriculum Development Center. (2005). Handbook of teaching and learning of values across the standard based curriculum for primary and secondary schools. Ministry of Education Malaysia.

Dalmacito, A. C. Jr. (2013). Moral decline in teens: The application of contextual theology. Asia-Pacific Social Science Review, 13(2), 24-40.

Durkheim, E. (1961). Moral Education: A study in the theory and application of theory. New York: Free Press.

Falikowski, A. (1990). Moral philosophy. Prentice Hall Publication.

Graham J., Meihdl, P., Beall, E., Johnson, K. M., \& Zhang, L. (2016). Cultural differences in moral judgment and behavior, across and within societies. Journal of Current Opinion in Psychology, 8. https://doi.org/10.1016/j.copsyc.2015.09.007

Gui, A. K. W., Yasin, M., Abdullah, N. S. M., \& Saharuddin, N. (2020). Roles of teacher and challenges in developing students' morality. Universal Journal of Educational Research, 8(3C), 52-59. https://doi.org/10.13189/ujer.2020.081606

Jalaluddin, N. H., \& Ahmad, Z. (2011). Hallyu in Malaysia: A sociological study. Journal Malaysian Communication, 27(2), 203-219.

Kant, I. (1979). Lectures on ethics. Translated by Infield, L. Methuen and Company Limited.

Kohlberg, L. (1958). The development of modes of moral thinking and choice in the years 10 to 16. Harper and Row.

Kotaiah, V. (2014). Role of the teacher in development of moral values. International Journal of English Language Literature.

Krech, D., \& Crutchfield, R. (1962). Individual in society. Mc Grawhill Kogakusha-LTD.

Lebar, O. (2012). Qualitative research. Introduction to theory and methods. Universiti Pendidikan Sultan Idris.

Maizura. (2015). Understanding of moral practice behave among Malay student Form Four in Putrajaya, Malaysia. Unpublished Doctoral Thesis, Universiti Putra Malaysia. Malaysia.

Malaysia Education Blueprint 2013-2025. (2012). Malaysia Education Ministry.

Melati, S., Zaharah, H., \& Saedah, S. (2010). Factors contributing to academic achievement and moral development: A qualitative study. The International Journal of Research and Review, 5(2), 18-23,

Ministry of Education Malaysia. (2016). Standard based curriculum for secondary schools form two moral education. Curriculum Development Division, Ministry of Education Malaysia.

Morgan, B. (2016). Is social media messing with children's morals? July 21. Retrieved from https://theconversation.com/ is-social-media-messing-with-childrens-morals-62579

Nietzsche, F. (1887). On the genealogy of morals. United States of America.

Othman, M. K. (2013). Implementation of pure value in teaching and its relation to the appreciation of pure value among secondary students. Unpublished Doctoral Thesis. Universiti Putra Malaysia. Malaysia.

Rashid, N. A. (2005). Politeness in the context of socio-cultural values Malay community. Journal of Studies.

Schwartz, S. H. (2007). Universalism values and the inclusiveness of our moral universe. Journal of Cross-Cultural Psychology, 38(6), 711-728. https://doi.org/10.1177/0022022107308992

Tan, W. N., \& Yasin, M. (2020). Parents' roles and parenting styles on shaping children's morality. Universal Journal of Educational Research, 8(3C), 70-76. https://doi.org/10.13189/ujer.2020.081608

Thiroux, J. P. (1977). For ethics: Theory and practice. Prentice Hall Publication.

Zajda, J. (2009). Values education and multiculturalism in the global culture. In J. Zajda, \& H. Daun (Eds.), Global Values Education Teaching Democracy and Peace. Springer. https://doi.org/10.1007/978-90-481-2510-4 


\section{Copyrights}

Copyright for this article is retained by the author(s), with first publication rights granted to the journal.

This is an open-access article distributed under the terms and conditions of the Creative Commons Attribution license (http://creativecommons.org/licenses/by/4.0/). 